\title{
Livros
}

\section{Emergências Psiquiátricas}

Flávio Kapczinski, João Quevedo, Ricardo Schmitt, Eduardo Chachamovich. Porto Alegre: Artmed Editora, 2001. 202 páginas. ISBN 85-7307-784-0

Apesar dos serviços de emergências psiquiátricas terem surgido na época da II Guerra Mundial para tratar e devolver rapidamente os soldados aos campos de batalha, foi com a reforma psiquiátrica e suas propostas que esses serviços se destacaram. Com o processo de desinstitucionalização e o fechamento de vários hospitais psiquiátricos do tipo "manicomiais", as indicações de internação psiquiátrica passaram a ser mais criteriosas, e a internação integral mais uma, e não a única, opção de tratamento do doente mental em crise, dividindo essa tarefa com serviços extra-hospitalares como hospitais-dia, pensões protegidas e ambulatórios.

Essa ênfase no tratamento extra-hospitalar levou a um aumento do número de pacientes sujeitos a descompensações na comunidade. Nesse contexto, inserem-se os serviços de emergências psiquiátricas, fazendo a interface entre a comunidade e as instituições de tratamento de saúde mental, oferecendo um atendimento rápido e ágil, buscando caracterizar diagnósticos clínicos e psicossociais do quadro apresentado pelo paciente, viabilizando uma intervenção imediata, e procurando orientar o tipo de tratamento com maior indicação para o caso em médio e longo prazo. A necessidade da intervenção imediata e a função decisória de encaminhamento de um caso trazem características próprias ao manejo de situações de emergência, tanto na avaliação do paciente, quanto na conduta proposta ao caso.

O trabalho realizado pelos autores em "Emergências psiquiátricas" reúne aspectos que auxiliam o manejo de situações de emergência. Aborda desde a avaliação do paciente, que na emergência deve ser objetiva e direta sem deixar de ser completa, até a multicausalidade que podem ter quadros como agitação psicomotora e delirium. Em um capítulo especial, abordam algumas patologias clínicas de maior relevância para a prática psiquiátrica, tanto pela gravidade quanto pela necessidade de um diagnóstico diferencial com patologias de origem psiquiátrica. Em quase todos os capítulos de situações de emergência, como delirium, agressividade e agitação psicomotora, risco de suicídio e outros, existem fluxogramas que apresentam de modo objetivo e claro formas de conduzir o caso e aspectos a ser considerados naquelas situações. Vale salientar ainda que houve, por parte dos autores, a preocupação de abordar temas que não são clíni$\cos$, mas que fazem parte da rotina diária dos profissionais que trabalham com emergências psiquiátricas, como abordagem ético-legal e social das emergências e manejo de vítimas de violência sexual.

É um texto prático, que possibilita consultas rápidas e apresenta, de forma sintética e objetiva, noções sobre epidemiologia, diagnóstico e, principalmente, tratamento em situações de emergências psiquiátricas. Abordando um tema que possui escassa literatura, tem grande utilidade para médicos e profissionais da área da saúde mental, e também pode ajudar os médicos que trabalham em emergências de hospitais gerais, onde intercorrências psiquiátricas também ocorrem com muita freqüência. Mesmo que não alcance as outras especialidades médicas, se atingir os profissionais da área da saúde mental, especialmente os que estão em formação, fornecendo meios e diretrizes para a condução de uma situação de emergência baseada nesse cuidadoso trabalho, já terá cumprido seu objetivo de qualificar esse tipo de atendimento.

\section{Maria Eugênia de Simone Brito dos Santos}

Setor de Emergência do Centro de Atenção Integrada à Saúde Mental da Santa Casa de Misericórdia de São Paulo 